\title{
GREENTECH: An Innovative IT Solution for Waste Management
}

\author{
Ma. Melanie Ablaza-Cruz, Thelma D. Palaoag
}

\begin{abstract}
Nowadays, mobile application development offers an innovative field for modernization. However, we cannot deny that we are facing the greatest environmental challenge, wastes management. Opportunities in enhancing the community's waste management practices have become easier with the progress of mobile application development. This paper aims to support every individual in strengthening their waste management practices within the community. The study focuses on designing a mobile application as an innovative IT solution in helping the community in improving its waste management. The researcher used a co-design methodology to define the content features, system requirements and to identify the user of the system. This framework and design consideration are recommended for utilization and implementation, to aid every member of the community in their waste management practices through an innovative solution. The result of the study helps individuals appreciate the importance of emerging technology in the solution to climate change. This shows that IT innovation is a great opportunity in improving the waste management habits of every individual. Somehow, this study helps individuals to recognize the importance of mobile technology as a solution to global concerns associated with climate change.
\end{abstract}

Keywords: Climate Change, Community, Mobile Technology, Waste Management

\section{INTRODUCTION}

As the population growth increases among developing countries, the issue of waste management also increases [1]. Hence, every individual has an important role in mitigating environmental challenges, climate change. In every municipality, solid waste management is a big challenge, primarily because of the high percentage of waste generation. Waste management is a real problem, poor communication and understanding across different of considerations that involve waste management [2] Environmental challenges are the present concern of many individuals and the advancement of a green economy is also a priority across countries [3]. Many advertisements and programs through social media are a line with global trends in sustainable development policies [3] [4] [5]. Different ways of engagement of both civil and policymaker is a good sign in improving waste management in the country.

One of the most important services provided by municipal authorities is waste management, this is essential services to every area within the society. Several researchers specified

Revised Version Manuscript Received on 10 September, 2019.

Ma. Melanie Ablaza-Cruz, Institute of Engineering and AppliedTechnology, Bulacan Agricultural State College, Bulacan, Philippines.

(Email: melanieablazacruz@gmail.com)

Thelma D. Palaoag, College of Information Technology and ComputerScience, University of the Cordilleras, Baguio City, Philippines. (Email: tpalaoag@gmail.com) that municipal solid waste has the highest percentage

contributor in the impacts of environmental problem especially global warming [6] [7] [8]. The Bureau of Environmental Management clearly stated that the majority in the residential area contributes within the community, this includes residues form the kitchen, backyard waste, papers, plastic and glass bottles and more [6] [7]. Base on the result of the study conducted by the World Bank organization, by the year 2050 it is estimated that the world possibly generates 3.4 billion tons of municipal solid waste annually [8].

The Philippines is not absolved in this problem, the problem in solid waste is highly crucial in every municipality. This is considered the most pressing environmental challenge in the country. It is projected that the solid waste generation will increase by $0.5 \mathrm{~kg} /$ day to 0.9 $\mathrm{kg}$ /day in 2025 , daily generation by 2025 is equal to 104,536 tons or about 38,155,640 tons annually [7] [9] [10].

Currently, mobile technology is very popular, it influences an individual in the changes in their behavior and lifestyle. For today, people are now using mobile phones everywhere. Technology nowadays has been employed to describe the ways how these new trends affect the way people go about their daily lives [1]. Mobile technology provides a greater opportunity in extending services to the community. The advances of mobile technology provide a great opportunity not only for the developer but also for the researcher to extend its services to the community.

Technology advancement can become a valuable tool for every individual by integrating the mobile application in environmental protection, waste recycling and waste prevention [11]. The different usage of technology nowadays unlocks the possibility for its several uses, where end-users develop different applications as practical tools for their interest and work [12]. However, taking into consideration that many individuals are aware of different usage of mobile technology, it is a real challenge for everyone to embrace the advantages of this technology in applying to waste management. Mobile phones can be a medium to have direct contact between people who are willing to participate in the zero-waste goal of the country. In social media, many citizens show their willingness to be part of the solution in helping the

country through waste management. The "trash tag challenge", where citizens are taking up photos on before and after cleaning specific area that is heavily littered, then sharing it to the community through social media to challenge other citizens to do the same [5]. Likewise, a group of volunteer individuals nationwide shows support in waste management, in a social media account entitled "Buhay Zero

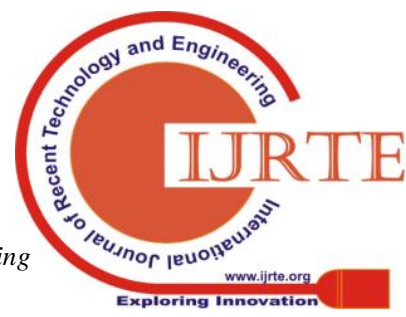


Waste", advertise different tricks on how to manage waste through recycling. The "eco-bricks" is one of their projects where they showcase the possible ways of recycling. These volunteer groups have more than 24,000 members who share their time, skills and knowledge about how to have an environmentally friendly lifestyle [13]. Obviously, in today's generation, many people are taking advantage of the usefulness of this emerging technology.

Despite the several efforts are being made by different organizations related to waste management, yet there are still major gaps to be filled in this area [14]. Additionally, even with numerous available mobile applications and researches concerning the refining the waste management and recycling habits have been presented [15] [16] [17]. There is still needs more study that would emphasize the individual level through the use of mobile applications [16]. However, studies conducted in this field, a lack of user-centered model in waste management habit support tools can be one of the causes [15][16]. This motivates the researcher in designing a framework for a mobile application that will support the waste management practice of every individual. The study aims to define an ICT solution as a helping tool for the community to improve its waste management. The Visual Table of Contents (VTOC) has been presented in this paper in order to show a top-down hierarchical structure of the proposed mobile application. Through VTOC the systems functions and its relationships can be examined, assessed, and can easily understood. This is one technique in helping the readers to understand the input, process and the output of the system. The researcher used the architectural framework to show the different features of the mobile application and its user. This study rants to prove if it can possibly help the individual realize that mobile technology can be part of a solution to environmental problems. Every individual can use this application. It will boost every citizen's involvement in waste management. Mobile technology has a great impact on the community once it is used properly. This study can reinforce every citizen within the community to be more responsible for their waste management. Through this application, simple household and different stakeholders have more opportunity to be part of a solution in the environmental and natural resources security issues in the country. Finally, this study helps readers to realize the importance of individual participation and mobile technology in helping the country in its sustainable development goals.

\section{METHODOLOGY}

An approval from the Municipal Mayor was sought before conducting the assessment and data gathering of the study. Likewise, a courtesy call was made to the barangay officials and the Head of the Municipal Environmental and National Resources Office (MENRO). The study utilized the Qualitative research approach to attain its objectives. The s Likert scale-based survey questionnaire was also distributed as a data-gathering tool. The sample size was also determined by using the stratified random sampling. This gives an equal chance for every individual in the population to be involved in the sample. Using the Slovin's formula, different respondents were randomly selected. A total of 467 residents (Household, Officials, Junkshop Owner, Store owner) of different barangay's served as respondents for this study. The design consideration in helping both household and community waste management habits in terms of architectural framework was determined through the use of co-design methodology. The Visual Table of Contents (VTOC) to show its content and features and to determine the users of the system. A guided questionnaire was used in conducting an in-depth interview with the respondents to identify the different users and desired content and features of the mobile application.

\section{RESULT AND DISCUSSION}

\section{The Proposed Architectural Design for the Mobile} Application

The designed architectural framework that would address the need of every individual regarding waste management through a mobile application is being presented in Figure 1.

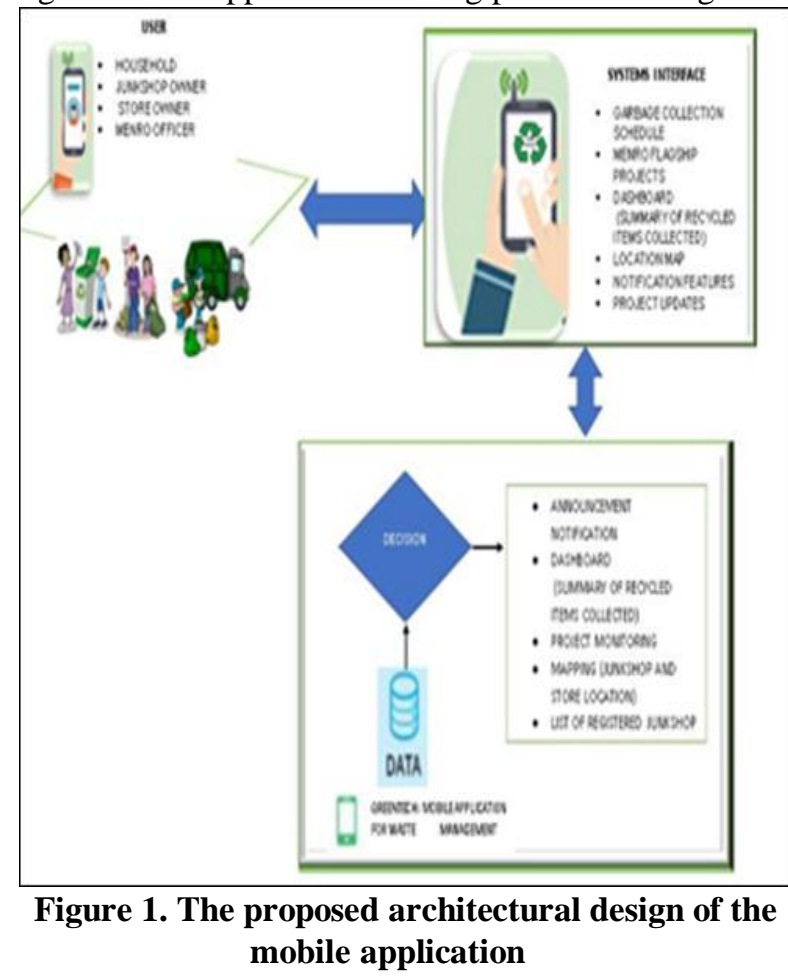

The mobile application can be used by the individual within the community to address the problems in waste management which is being shown in Figure 1. It includes the different identified features as the result in the interview and data gathering conducted with the stakeholders. Thus, the identified user of the system was the different member of the community, namely: Household, Municipal and Environmental Resource officer (MENRO), the owner of the junk shop and participating store in the barangay. This will answer the problem regarding the people engaged in their participation in waste management since in some studies they have found out that a user-centered design was lacking in the existing mobile application [11]. They are being identified based on their possible contribution to waste management within the community. After the conducted set of interviews on different stakeholders of the community, the features and

Blue Eyes Intelligence Engineering

\& Sciences Publication 
functionalities of the system have been finalized. The researcher successfully identified the following features: First is the Garbage collection schedule, this provides setting and viewing of the schedule of garbage collection in every barangay. This feature will automatically inform every individual in any updates in their area. Also, the MENRO officer will be able to monitor the staff who was assigned in the collection, because in this feature there is a form where the staff can update the remarks if ever the garbage has been collected or not. Secondly, the MENRO project flagship features.

This part of the system will provide a form that will cater to the different programs of the MENRO office. Monthly Clean-up drive form, where every barangay can upload photos and updates regarding their compliance in the said project at the same time. This feature will inform the MENRO office regarding the participation of every barangay in this program. The Palit-Basura project form, where the store owner can update the MENRO office on the list of the summary on the different recycled items which they have been collected from the different residences in every barangay. In this form, the administrator will be aware of the number of the collected recycled items and used this data for policymaking techniques. Lastly, was the Segregation at Source and campaign on solid waste management, where the MENRO can use the application to advertise this project and reach out to every individual within the community.

The application also has a dashboard form, this part will be used to let the administrator easily views the summary of the different list of the registered user of the system, and one important thing in this feature was the summary report of the collected item through junkshop and store owner. The location Map feature will be very helpful for every household, especially those who were not able to go to different junkshop to trade their recycled items. Household owners may be able to use the location map to view the nearby junk shop and choose where they can trade their items. In this feature, the household can request the junkshop owner to go to their house to collect their item. Also, the junk shop will have a form to notify the household regarding their request if it is accepted or not. This feature will also help the junkshop owner to be easily identified as the exact location of their customer.

\section{Importance of the proposed mobile application}

Every possible user of the system is required to register first before signing up on the application. This will help the MENRO to identify the certified store and junkshop businesses, for in every store and junkshop owner must upload the copy of their business permit at first, then the documents would be verified by the administrator before accepting the registration request This will be better for the municipality to identify those business establishments to ensure that they have followed the policies specified by the office. For the Junkshop owner, it will be a great avenue for them to have direct contact with their customers. Through the mobile application, the business owner will have more opportunities to earn money and to participate in waste management within its area.

Through this IT intervention, every household will have direct contact to the junkshop owner to be able to trade its recyclable items into cash. This will help the household to appreciate the importance of waste segregation in their homes and earn additional income through it. Also, the mobile application will give the option to trade the recycled items directly to the participating store into grocery items. Moreover, in this way, the involvement of every individual on waste recycling and waste management within the municipality will be enhanced. Following the above considerations, it would be able to easily be identified and target specific consumers. Everyone will engage themselves in using the mobile application in mitigating climate change.

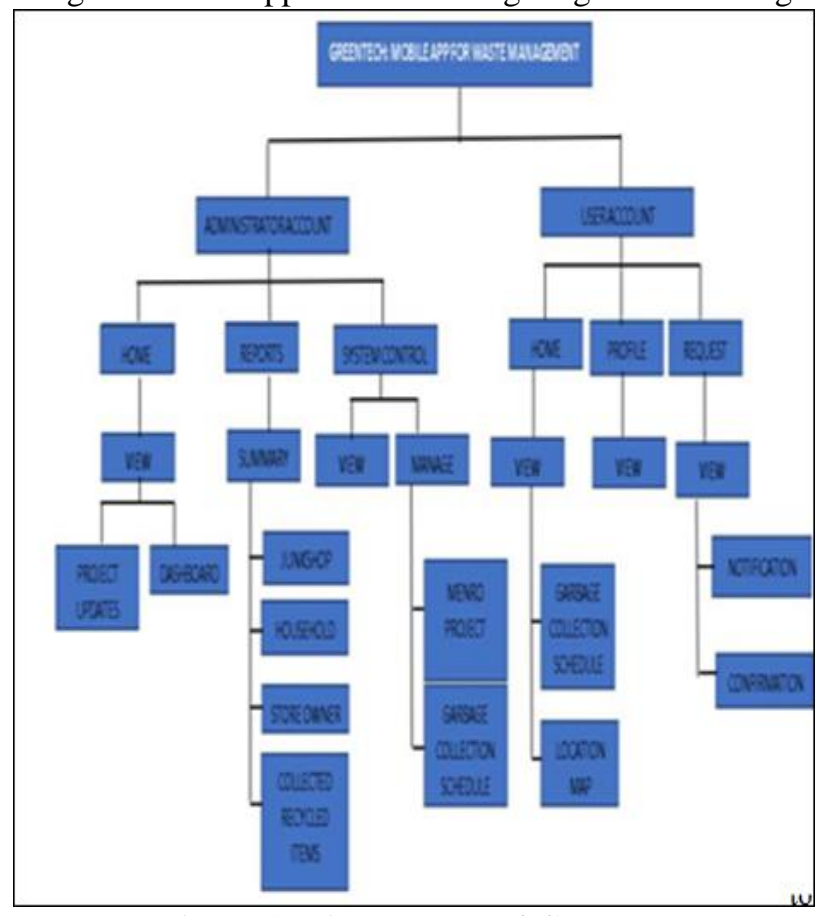

Figure 2. Visual Table of Contents

The Visual Table of Contents (VTOC) diagram is shown in Figure 2. This figure is used to illustrate the hierarchical links of the proposed mobile application for waste management. The figure shows the different user account of the application. Also, in this figure the different menus in the system were defined. Upon the login process, the administrator has three menu options that will appear on the navigation formof the system. The three navigation menus that the administrator can manipulate are as follows: Home, Reports and System Control. In the Home menu, the administrator has two options to view, the dashboard and the project's updates. In the Report menu, the administrator can navigate the three buttons which include the summary of the different transactions in the system. The administrator can choose the type of statistical report to be generated by the system such as a summary of the registered junkshop and store owner, and the number of household users. Moreover, one of the important options in the report menu was the summary of the collected recyclable materials.

This feature can help the administrator (MENRO Officer) to find out how individual manage their household trash. This will possibly help the MENRO office to take into consideration on policymaking regarding waste management 
Likewise, in this menu, the MENRO officer could probably monitor the different barangay who participated in their waste management projects like the cleanup drive, by viewing the content on the Update button. Through this feature, they can come up with different alternative projects, if ever it is needed too. In the User account, it has three menu options. In the Profile menu, the user can manage or manipulate his/her personal information. The Request menu option, the household can request for a junkshop owner to pick up its recyclable items. While in the Home menu, the user can view the Garbage collection schedule and be updated on any announcement regarding waste management. Also, the location map button will help the user to view the location of the nearby junk shop and the store owner.

\section{CONCLUSION}

Improper waste disposal problems are not that new to everyone, in fact even the youngest generation today is more aware of this main problem of every municipality. The total participation of every individual in helping the government in this concern is highly to encourage. Every individual must be responsible and be part of the solution in this concern. In this paper, the advancement of mobile technology has been studied and apply in conceptualizing a mobile application framework, which caters every individual to their waste management habits. By taking into consideration that in today's lifestyle, mobile technology is becoming a necessity for every individual, and because of the declining price of mobile phones nowadays even simple individual is using it. For that reason, this mobile application can be adopted in any municipalities to help citizens to be part of a solution in mitigating the climate change issues not only in their areas but also in the countries.

By implementing this application, it will be easier for the municipalities to have communication with every member of the community it serves. Through the intervention of the IT innovation, the study gives a possible solution in improving the waste management habit of an individual. The study is beneficial to every member of the community. This also increases the responsiveness of every household and stakeholders in participation in any waste management programs of the municipalities. Hence, support from the Local Government Unit (LGU) would further consider. Finally, for the continuous improvement of the proposed mobile application, it would be better if a study regarding the assessment of the functionalities and level of acceptability will be conducted.

\section{REFERENCES}

1. A. M.K.Ghosea, "A GIS-based transportation model for solid waste disposal - A case study on Asansol municipality," Waste Management, vol. 26, no. 11, pp. 1287-1293, 2006.

2. G. LillianaAbarcaGuerrero, "Solid waste management challenges for cities in developing countries for cities in developing countries," Elsevier, vol. 33, no. 1, pp. 220-232, 2013.

3. V. A. P. YuliaVertakova, "Problems of sustainable development worldwide and public policies for a green economy," Інституттрансформаціїсуспільства, nо. 7-8, pp. 4-10, 166/2017.

4. "NewBytes Philippines. (2013)," [Online]. Available: http://newsbytes.ph/2016/03/02/e-basura-app-from-uc-tops-20 15-ph-sta rtup-challenge/. [Accessed March March 2019].

5. Unilever Philippines, "Facebook," 16 march 2019. [Online]. Available:

https://www.facebook.com/BeatPlasticPollutionPH/posts/540 435906363837.

6. Putthakasem, "Scenarios of Municipal Solid Waste Mangement for Mitigating Greenhouse Gas Emission," in 7th International Conference on Informatics, Environment, Energy, and Applications, 2018.

7. Environmental Management Bureau, "Solid WasteEnvironmental Management Bureau," [Online]. Available: https://emb.gov.ph/wp-content/uploads/2018/09/3-Solid-Wast e-1.8.pdf

8. World Bank. org, "Global Waste to Grow by 2050 Unless Urgent Action is Taken:" World Bank Report, Washinton, September 2018 Press Release No: 2018/037/S. [Online]. [Accessed April 2019].

9. S. Grace, "Solid Waste Management and Sustainable Development: The Case of Philippine Cities," in International conference in Urban and Regional Planning, 2018.

10. I. \&. K. J. Williams, "Green waste collections and public recycling behavior in the borough of Wyre resources, Conservation and Recycling," Elsevier Applied Science Publisher, Vols. vol. 38, 139-159, 2003.

11. Bonino, Pastrone, Delgado, and Spirito, "WasteApp: Smarter Waste Recycling for Smarter CItizens," Splitech 2016, 2016.

12. Tran, "International Journal of Pervasive Computing and Communications," vol. 10, no. 2, 2014.

13. V. L. Tantuco, "Why can't the Philippines solve its trash problem?" Rappler, 14 September 2018. [Online]. Available: https://www.rappler.com/newsbreak/in-depth/210292-reasonphilippin es-cannot-solve-trash-problem. [Accessed 10 August 2019].

14. P. Aljaradin, "Comparison of Different Waste Management Technologies and Climate Change Effect-Jordan," American Journal of Climate Change, pp. 57-63, 2012.

15. Bamodu, "Application of Mobile Technology in Waste Collection," International Journal of Applied Sciences (IJAS), 2013.

16. A. Mavropoulus, "D-WASTE: Mobile Applications \& Waste

17. Management: Recycling, Personal Behavior, Logistics," Research gate, May 12, 2015.

18. M. T. A. A. AntonisMavropoulos, "Urban Waste Management and the mobile challenge," Waste Management and Research, 2015.

19. L. Qiu, J. Lu, S. Yang, W. Qub and T. Zhu, "What does your selfie say about you?" Computers in Human Behavior, pp. 443-449, 2015

20. H. Oza, "The Importance of Mobile Applications in Everyday Life!" 28 March 2017. [Online]. Available: https://www.hyperlinkinfosystem.com/blog/the-importance-of -mobile-applications-in-everyday-life. [Accessed August 2019].

21. V. L. Tantuco, "Why can't the Philippines solve its trash problem?" 2018.

22. A. T. Mavropoulos, "D-WASTE.com," 12 May 2015. [Online]. Available: http://www.d-waste.com.

23. C. A. V. David C Wilson, "Waste management - still a global challenge in the 21st century: An evidence-based call for action," Waste Management \& Research, vol. 33(12) 1049-1051, no. sagepub.co.uk, 2015. 


\section{AUTHORS PROFILE}

Ma. Melanie Ablaza-Cruz- -is currently enrolled at the University of the Cordilleras, Baguio City taking up Doctor in Information Technology. An IT Instructor and a Research Coordinator in the Institute of Engineering and Applied Technology at Bulacan Agricultural State College, Philippines.

Thelma D. Palaoag-is the Graduate School Coordinator inthe Collegeof Information Technology and Computer Science of University of the Cordilleras, Philippines. 